\title{
Scleral buckle surgery in Ghana: a decade comparison of the anatomic and visual outcome
}

This article was published in the following Dove Press journal:

Clinical Ophthalmology

\author{
Imoro Z Braimah ${ }^{1,2}$ \\ Stephen Akafo ${ }^{1,2}$ \\ Jay Chhablani ${ }^{3}$
}

'Department of Surgery, School of Medicine and Dentistry, College of Health Sciences, University of Ghana, Accra, Ghana; ${ }^{2}$ Eye Centre, Korle Bu Teaching Hospital, Accra, Ghana; ${ }^{3}$ Srimati Kanuri Santhamma Centre for Vitreo-Retinal Diseases, KAR Campus, L V Prasad Eye Institute, Hyderabad, Telangana, India
Correspondence: Imoro Z Braimah Department of Surgery, School of Medicine and Dentistry, College of Health Sciences, University of Ghana, PO Box 4236, Accra, GA-320, Ghana Tel +23320630 I353

Email zebaimoro2000@yahoo.com
Purpose: To compare the anatomic and visual outcome of scleral buckle (SB) surgery in Korle Bu Teaching Hospital between 2002 and 2005 and 2011 and 2014.

Materials and methods: In this retrospective comparative study, the medical records of patients who have undergone SB for rhegmatogenous retinal detachment from January 2002 to December 2005 (group A) and from January 2011 to December 2014 (group B) in Korle Bu Teaching Hospital were examined. The clinical history, surgical techniques, and outcomes of treatment were analyzed. The main outcome measures were primary anatomic success (retina reattached for at least 3 months postoperatively after a single procedure), overall anatomic success (combined primary anatomic success and success following revision of SB with at least 3 months follow-up), mean postoperative best-corrected visual acuity (BCVA), and complications.

Results: One hundred fifty-eight eyes (71 eyes in group A and 87 eyes in group B) were treated with SB in this study. The mean duration of rhegmatogenous retinal detachment was 105.5 days. Thirty-four (21.8\%) of fellow eyes had BCVA worse than $6 / 60$ at presentation. The primary anatomic success was comparable between the two groups; $70 \%$ in group A and $67.9 \%$ in group $\mathrm{B}(P=0.79)$. The overall anatomic success was also comparable between the two groups $(76.7 \%$ in group A vs $79.8 \%$ in group B) $(P=0.788)$. The mean postoperative BCVA in logMAR was significantly better than the mean preoperative BCVA $(P<0.0001)$. Group B had significantly better mean BCVA $(P=0.002)$ and longer duration of follow-up $(P<0.0001)$ compared with group A at the last follow-up visit.

Conclusion: The anatomic success of SB between the two time periods was comparable. A longer postoperative duration of follow-up was associated with a better visual outcome after SB.

Keywords: rhegmatogenous retinal detachment, scleral buckle surgery, laser retinopexy, cryotherapy, Ghana

\section{Introduction}

The main surgical methods for the treatment of rhegmatogenous retinal detachment (RRD) are scleral buckle (SB) surgery and pars plana vitrectomy (PPV). SB is an effective procedure for treating RRD. ${ }^{1-4}$ The anatomic success rate of SB surgery has been reported to range from $75 \%$ to over $90 \% .{ }^{1-4}$ Macular detachment and its duration are the most important prognostic factors for visual outcome, and macular detachment is consistently associated with poorer visual outcome. ${ }^{4,5}$ Although the duration of macular detachment is a significant prognostic factor, there is no consensus on the exact duration after which visual recovery may be compromised. ${ }^{4-8}$ It is becoming increasingly clear that the visual outcome of SB done in the first week of macular-off RRD is not influenced by duration. ${ }^{4-8}$ In a meta-analysis of RRD treated with SB, van Bussel et al reported that SB must be performed within 3 days of macular detachment to optimize the visual outcome. ${ }^{9}$ 
Because of lack of awareness of RRD, delay in diagnosis of RRD, limited availability of facilities, and poverty level in Ghana, patients with RRD often present late and a significant proportion present with complicated disease that would usually have been treated with PPV in the developed world. ${ }^{10}$ PPV requires the use of expensive technology, and the cost of surgery is higher compared with SB surgery. Before the year 2013, SB was the only surgical procedure performed regularly in Ghana due to lack of equipment and skilled personnel for PPV. SB is the main surgical procedure performed in Korle Bu Teaching Hospital (KBTH) over the past two decades. From the year 2011, there was a change in the technique of SB surgery in KBTH with the adoption of minimally invasive techniques. However, there are no studies on the anatomic success and visual outcome of SB surgery in a Ghanaian population so far. This study seeks to determine the success of SB surgery and the differences in the anatomic success and visual outcome between two time periods.

\section{Materials and methods}

In this retrospective study, all patients with RRD who were treated with SB at the Eye Centre of KBTH, Ghana, from January 2002 to December 2005 and from January 2011 to December 2014 were included. This study adhered to the tenets of the Declaration of Helsinki and was approved by the institutional review board of KBTH (KBTHIRB/00036/2016).

\section{Inclusion criteria and exclusion criteria}

Eyes were eligible for this study if they had RRD or combined rhegmatogenous and tractional retinal detachment and had undergone SB only.

The diagnosis of retinal detachment was made clinically and included history of one or all of the following: sudden loss of vision, visual field defect, floaters, and flashes of light, supported by retinal configuration typical of RRD whether the primary break was seen or not. The presence of tractional fibrovascular membranes did not exclude eyes from this study.

Exclusion criteria included eyes with RRD that did not undergo SB and tractional retinal detachment or exudative retinal detachment.

\section{Demographic and clinical data}

The demographic and clinical characteristics of the patients recorded included preoperative variables such as age, sex, affected eye, symptoms, duration of detachment, medical history, preoperative visual acuity, refractive status, lens status, the type, number and location of retinal breaks, extent of detachment, macular status and presence of proliferative vitreoretinopathy (PVR), operative variables such as buckle type, subretinal fluid (SRF) drainage, type of retinopexy and complications, and postoperative variables such as reattachment status and visual acuity at 1, 3, 6, and 12 months and at the last follow-up visit, postoperative complications, and status of the fellow eye.

\section{Surgical procedure}

SB was performed by two surgeons (SA and IZB). Under local anesthesia with 50:50 mixture of 2\% xylocaine and $0.5 \%$ plain bupivacaine using peribulbar anesthesia and aseptic technique, peritomy was made at the limbus. The limbal peritomy was limited to the quadrant of the primary break when placement of segmental buckle was planned or extended to 360 degrees in the case of placing encircling band. Traction sutures were placed underneath the recti using 4-0 silk suture. The sclera is inspected for the presence of scleral thinning. Indirect ophthalmoscope examination was done to localize retinal break(s) and areas of peripheral retinal degenerations. Mattress suture(s) are placed using 5-0 Mersilene and the suture knots tied using releasable suture technique. SRF drainage was done using 25 gauge 5/8 inches hypodermic needle when planned. Cryotherapy was performed around the edges of retinal break(s) in group A. Encircling band (type 240), $5 \mathrm{~mm}$ sponge (type 505) or $7.5 \times 5.5 \mathrm{~mm}$ sponge (type 507 ) were placed and secured using preplaced 5-0 Mersilene mattress sutures. Retina examination using indirect ophthalmoscope was done to confirm correct placement of the buckle and for pulsation of the central retinal artery. The sub-Tenon's space is irrigated with gentamicin and conjunctiva closed using 8-0 polyglactin 910 (Vicryl) suture. The eye is closed and patched. The minimally invasive buckle surgery in group B included limited peritomy, the use of segmental buckles instead of encircling bands, and nondrainage of SRF without retinopexy of retinal break. Laser retinopexy is done on postoperative day 1 or whenever adequate visualization is allowed in group B.

The patients were seen on postoperative days 1 and 7 , and at 1 and 3 months and there after every 3 months for the first year. Postoperative treatment included guttae (gtt) prednisolone $1 \%$ qid for at least 1 month, gtt ciprofloxacin $0.3 \%$ qid, and gtt cyclopentolate $1 \%$ bid for 1 week. Raised intraocular pressure was controlled with oral acetazolamide $250 \mathrm{mg}$ bid, gtt timolol $0.5 \%$, and gtt brimonidine tid. 


\section{Statistical analysis}

SPSS version 20.0 was used for data analysis. Data were presented using frequency tables and figures as appropriate. The anatomic success rate (ratio of flat retina to total number of patients operated) at 1, 3, 6, and 12 months postoperatively and at the last follow-up visit was computed for each group. Primary success (single operation success) is defined as retina reattached for at least 3 months postoperatively. Secondary success is defined as retina reattached for at least 3 months after revision of SB and overall success include primary and secondary success. Snellen visual acuity was converted to the logarithm of minimum angle of resolution $(\log$ MAR) for statistical analysis. The mean visual acuities at 1, 3, 6, and 12 months postoperatively and at the last follow-up visit were determined. Continuous data were presented as mean and SD. Independent $t$-test and Mann-Whitney $U$ test were used to compare continuous data between the two groups. Chi-square and Fisher's exact tests were used to compare categorical data. The effect of preoperative, operative, and postoperative variables on anatomic success and visual outcome was determined by univariate and multiple regression analysis. $P$-values $<0.05$ was considered statistically significant.

\section{Results}

\section{Demographic and clinical characteristics}

One hundred fifty-eight eyes (71 between 2002 and 2005 and 87 between 2011 and 2014) of 156 patients who had SB were included in this study. The mean $( \pm S D)$ age of the patients was $47.9 \pm 14.6$ years (range, $13-81$ years) and 112 of them were males. The patients operated between these two time periods had similar baseline clinical characteristics (Table 1). The primary break was seen in $62(87.3 \%)$ eyes in group A and 82 (94.3\%) eyes in group B. Associated vitreous hemorrhage was found in three (4.2\%) eyes in group A and in eight (9.2\%) eyes in group B. Fourteen (16.1\%) eyes had grade A, 23 (26.4\%) eyes had grade B, and 29 (33.3\%) had grade $\mathrm{C} 1$ or worse PVR, respectively, in group $\mathrm{B}$ while 20 eyes $(28.2 \%)$ had grade $\mathrm{C} 1$ or worse PVR in group A. These was no significant difference in the rate of grade $\mathrm{C} 1$ or worse PVR between the two groups $(P=0.527)$. Retinal pathologies detected in other quadrants in the affected eyes include (number): lattice degeneration (12), fibrovascular membranes (5), pigmentary retinal degenerations (1), choroidal detachment (3), chorioretinal scars (1), retinal breaks (5), and secondary macular hole (3) in group B. Similarly, pathologies detected in other quadrants include (number): lattice degeneration (17), fibrovascular membranes (3), and choroidal detachment (1) in group A. The systemic comorbidities of the patients include (number in group A/group B): hypertension (11/19), diabetes mellitus ( $0 / 2)$, and sickle cell disease or trait (5/12). The mean postoperative follow-up in months was longer in group B $(16.81 \pm 11.17)$ compared with group A $(6.91 \pm 10.79)(P<0.0001)$.

\section{Anatomic outcome}

Encircling, segmental (radial and circumferential segmental), and combined (encircling with segmental) buckling were performed in 42 (59.2\%), 18 (25.3\%), and 11 (15.5\%), respectively, in group A compared with 25 (28.7\%), 58 $(66.7 \%)$, and 4 (4.6\%), respectively, in group B ( $P=0.6847)$. SRF drainage was performed in 67 (94.4\%) eyes in group A and in $28(32.2 \%)$ eyes in group B. Intraoperative cryotherapy was performed exclusively in group A, while postoperative laser retinopexy was performed in group B.

The primary anatomic success in group A was $42 / 60$ (70\%) compared with 57/84 (67.9\%) in group B. The overall anatomic success (primary and secondary success combined) was 47/62 (75.8\%) in group A compared with 67/84 (79.8\%) in group B. The anatomic success at different time periods after SB is summarized in Figure 1.

In group $\mathrm{A}$, the preoperative duration of macular detachment of $>1$ month and PVR were significantly associated with a poorer anatomic success by univariate analysis $(P=0.02)$ and $(P<0.0001)$, respectively, and only PVR was significant $(P<0.0001)$ by multivariate analysis in group $\mathrm{A}$. In group $\mathrm{B}, \mathrm{PVR}(P=0.019)$ and vitreous hemorrhage associated with RRD at presentation ( $P=0.013)$ were significantly associated with a poorer anatomic success by univariate analysis, but only macular detachment $(P=0.02)$ was significant by multivariate analysis.

\section{Revision of SB}

In group A, 18 eyes had primary failure. Nine of these eyes had PVR grade $\mathrm{C}$, four had anteriorly placed encircling bands relative to the primary break, two had missed break, one had tractional fibrovascular membrane over the break from sickle cell disease, and in two eyes no break was seen preoperatively and intraoperatively. Nine eyes had further procedures, and these include augmentation of encircling band with silicone sponge type 507 (five eyes), augmentation of buckle with encircling band type 240 (two eyes), and repositioning of silicone sponge (two eyes). Five (55.5\%) eyes that had SB revision achieved a secondary anatomic success. Four eyes that initially achieved primary anatomic success had redetachment (secondary failure) of their retina at $6,10,12$, 
Table I Baseline characteristics of I58 eyes undergoing scleral buckle surgery in Korle Bu Teaching Hospital

\begin{tabular}{|c|c|c|c|}
\hline Parameters & $\begin{array}{l}2002-2005 \text { (Group A) } \\
N=7 \mid\end{array}$ & $\begin{array}{l}20 I I-20 I 4 \text { (Group B) } \\
N=87\end{array}$ & $\begin{array}{l}\text { P-value } \\
\text { (2-tailed) }\end{array}$ \\
\hline Age, years, $X \pm S D(C l)$ & $46.6 \pm 14.8(43.2-50.1)$ & $48.9 \pm 14.37(45.8-52)$ & 0.190 \\
\hline Sex (male/female) & $54 / 17$ & $58 / 29$ & 0.568 \\
\hline Duration of symptoms, days, $\mathrm{X} \pm \mathrm{SD}(\mathrm{Cl})$ & $75.8 \pm 66.2(59.9-91.8)$ & $130.5 \pm 294.2(66-195)$ & 0.199 \\
\hline $\begin{array}{l}\text { Symptoms, yes/no } \\
\text { Blurred vision } \\
\text { Floaters } \\
\text { Flashes of light }\end{array}$ & $\begin{array}{l}70 / 1 \\
25 / 9 \\
23 / 17\end{array}$ & $\begin{array}{l}83 / 4 \\
58 / 9 \\
56 / 12\end{array}$ & $\begin{array}{l}0.832 \\
0.363 \\
0.05\end{array}$ \\
\hline $\begin{array}{c}\text { Known history of } \\
\text { Myopia } \geq-6 D \\
\text { Myopia }<-6 D\end{array}$ & $\begin{array}{l}7 \\
7\end{array}$ & $\begin{array}{l}6 \\
44\end{array}$ & 0.002 \\
\hline IOP mmHg, X \pm SD (Cl) & $12.64 \pm 4.33(11.6-13.6)$ & $12.9 \pm 4.8(|1.9|-13.94)$ & 0.724 \\
\hline $\begin{array}{l}\text { Lens status } \\
\text { Phakia } \\
\text { Pseudophakia } \\
\text { Aphakia }\end{array}$ & $\begin{array}{l}66 \\
4 \\
1 \\
\end{array}$ & $\begin{array}{l}81 \\
5 \\
1 \\
\end{array}$ & 0.989 \\
\hline $\begin{array}{c}\text { Macular status } \\
\text { Macular off } \\
\text { Macular on }\end{array}$ & $\begin{array}{l}64 \\
7 \\
\end{array}$ & $\begin{array}{l}79 \\
8 \\
\end{array}$ & 0.347 \\
\hline $\begin{array}{l}\text { Number of breaks seen } \\
\text { I } \\
\text { More than I } \\
\text { Not seen }\end{array}$ & $\begin{array}{l}33 \\
31 \\
1\end{array}$ & $\begin{array}{l}46 \\
36 \\
5\end{array}$ & 0.361 \\
\hline $\begin{array}{l}\text { Primary break location, N (\%) } \\
\text { Superotemporal } \\
\text { Inferotemporal } \\
\text { Superonasal } \\
\text { Inferonasal } \\
\text { Temporal } \\
\text { Superior } \\
\text { Nasal } \\
\text { Inferior } \\
\text { Unknown } \\
\text { Total }\end{array}$ & $\begin{array}{l}31(50) \\
16(25.8) \\
7(11.3) \\
3(4.8) \\
2(3.2) \\
3(4.8) \\
- \\
- \\
- \\
62\end{array}$ & $\begin{array}{l}47(57.3) \\
17(20.7) \\
6(7.3) \\
3(3.7) \\
4(4.9) \\
\text { I }(1.2) \\
- \\
\text { I }(1.2) \\
3(3.7) \\
82\end{array}$ & \\
\hline
\end{tabular}

Abbreviations: $\mathrm{N}$, number; $\mathrm{X}$, mean.

and 18 months postoperatively, respectively. The cause of redetachment was PVR in all the eyes. No further procedure was performed in eyes with secondary failure.

In group B, 27 eyes had primary failure and the cause of the failures include PVR grade C (19), missed break (6), fish mouthing of break (1), and tractional fibrovascular membrane over the break from sickle cell disease (1). Fourteen eyes had further surgical procedures and these include repositioning of segmental circumferential buckle (9), augmentation of buckle with radial sponge (3), augmentation of buckle with encircling band (1), and repositioning of radial sponge (1). Secondary anatomic success was achieved in $10(71.4 \%)$ eyes that had further surgical procedure. Three eyes that initially achieved primary anatomic success had redetachment of their retina at 6,12 and 24 months postoperatively, respectively. The cause of the retinal redetachment in the three eyes was due to PVR. One patient with secondary failure at 12 months from reopened horseshoe tear due to PVR had successfully attached retina after augmentation of buckle with encircling band.

\section{Visual acuity results}

The mean $( \pm \mathrm{SD})$ preoperative best-corrected visual acuity (BCVA) in logMAR was similar between the two time periods, thus, 2.01 \pm 0.94 in group A vs 1.93 \pm 1.04 in group B $(P=0.667)$. There was a tendency for improvement in mean postoperative BCVA with the duration of follow-up. The mean $( \pm \mathrm{SD})$ postoperative BCVA in group $\mathrm{A}$ at $1,3,6$, and 12 months were $1.41 \pm 0.73,1.25 \pm 0.86,0.88 \pm 0.87$, and $0.83 \pm 1.04$, respectively. The mean $( \pm \mathrm{SD})$ postoperative 


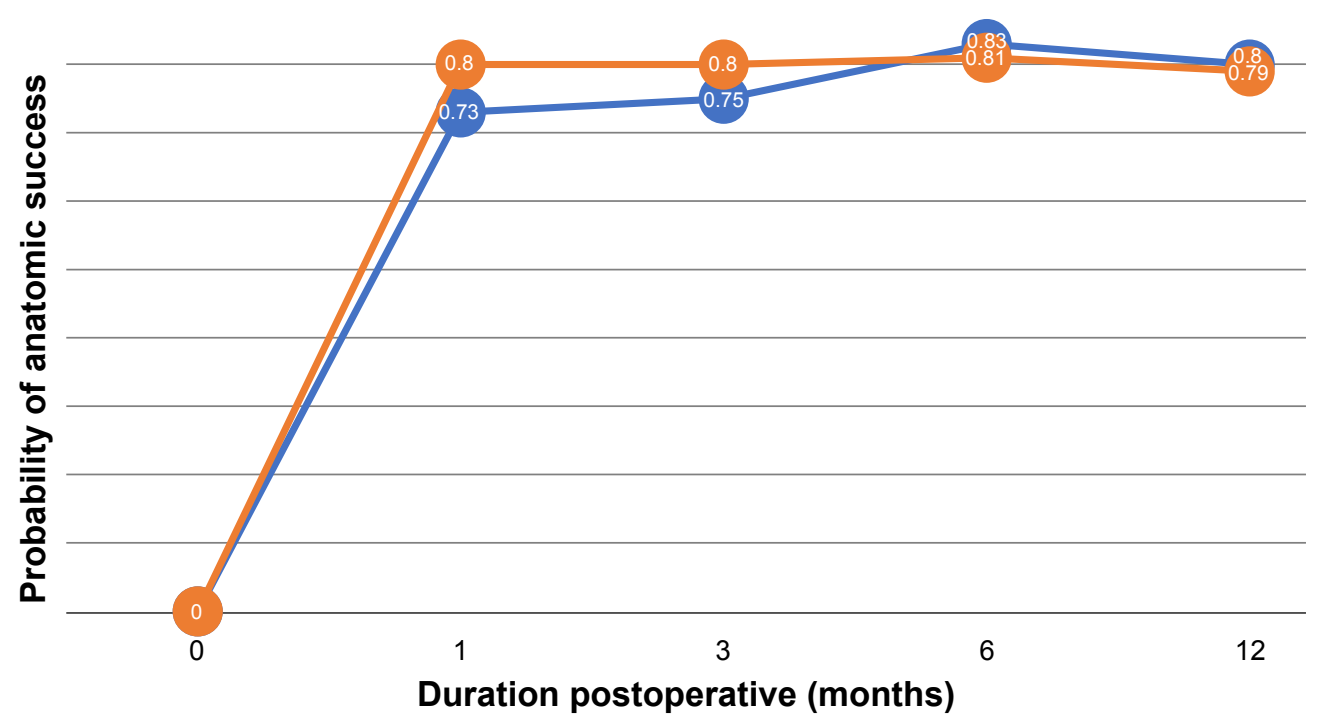

2002-2005 - Number at risk (complete anatomic success): 71 (0), 63 (46), 62 (47), 35 (29), 15 (12)

2011-2014 - Number at risk (complete anatomic success): 87 (0), 86 (69), 84 (67), 80 (65), 58 (46)

Figure I Anatomic success in months for groups A and B. Both groups had similar anatomic success at I month postoperative, and the anatomic success was maintained up to 12 months postoperatively.

BCVA in group B at 1, 3, 6, and 12 months were 1.14 \pm 0.73 , $1.01 \pm 0.82,0.90 \pm 0.78$, and $0.78 \pm 0.78$, respectively. There was a significant improvement in the mean postoperative BCVA in group B compared with group A at 1 month postoperatively $(P=0.027)$. However, there was no significant difference in the mean postoperative BCVA between group $\mathrm{A}$ and $\mathrm{B}$ at $3(P=0.094), 6(P=0.903)$, and $12(P=0.837)$ months, respectively.

Overall, the mean postoperative BCVA at the last follow-up visit (1.02 \pm 0.896$)$ was statistically significantly better than the mean preoperative BCVA $(1.967 \pm 0.995)$ $(P<0.0001)$. Group B had a longer mean duration of follow-up postoperatively (16.81 \pm 11.17 months) compared with group A $(6.91 \pm 10.79$ months $)(P<0.0001)$. The mean postoperative BCVA at the final follow-up visit in group B $0.81 \pm 0.80$ (approximate Snellen equivalent 6/37.5) was statistically significantly better than in group A $1.25 \pm 0.95$ (approximate Snellen equivalent 6/96) $(P=0.0021)$.

In group $\mathrm{A}$, preoperative visual acuity $(P<0.0001)$, macular-off detachment $(P<0.0001)$, and PVR $(P<0.0001)$ were significantly associated with postoperative visual acuity of $3 / 60$ or worse by univariate analysis, but only duration of macular detachment of $>1$ month prior to SB $(P=0.04)$ was significant by multivariate analysis. In group $\mathrm{B}$, preoperative visual acuity $(P=0.019)$, vitreous hemorrhage $(P=0.002)$, and secondary macular hole associated with RRD $(P<0.0001)$ and PVR $(P<0.001)$ were significantly associated with postoperative visual acuity of
3/60 or worse and only macular-off RRD was significant by multivariate analysis.

\section{Complications}

All intraoperative complications observed were related to drainage of SRF. Two eyes developed subretinal hemorrhage in group A and one eye developed vitreous hemorrhage in group B. The postoperative complications recorded include (2002-2005/2011-2014): transient diplopia (1/2), persistent corneal epithelial defect $(0 / 1)$, raised intraocular pressure (4/13), cataract (3/11), new break (0/1), PVR grade C development/progression (5/9), implant extrusion (1/1), epiretinal membrane (1/1), and sensory exotropia (3/6).

\section{Status of fellow eye}

In group $\mathrm{A}$, one patient had $\mathrm{SB}$ in the fellow eye. Of the remaining 70 fellow eyes, the pathologies detected at presentation include old retinal detachment (15), retinal breaks (9), lattice degeneration (7), proliferative sickle cell retinopathy (2), corneal scar (1), and anophthalmia following evisceration (1). Similarly, in group B, one patient had SB in the eye and of the remaining 86 fellow eyes, the pathologies detected at presentation include old retinal detachment (18), retinal breaks (10), lattice degeneration (8), cataract (3), aphakia (1), phthisis bulbi (2), vascularized corneal scar (1), chorioretinal scars (3), pigmentary retinal degeneration (1), spontaneously attached retina (1), proliferative sickle cell retinopathy (5), and peripheral retinal arteriolar occlusion (1). 
Fifty-five (78.6\%) fellow eyes had visual acuity of 6/60 or better, while $15(21.4 \%)$ had visual acuity worse than $6 / 60$ in group A. Of the 15 fellow eyes with poor visual acuity at presentation, five had counting finger vision, two had hand motion vision, two had perception of light vision, and six had nonperception of light vision. The cause of poor vision in 15 eyes includes old retinal detachment considered inoperable by SB in 14 eyes and anophthalmia following evisceration in one eye.

In group B, 67 (77.9\%) fellow eyes had 6/60 or better acuity at presentation and 19 (22.1\%) eyes had visual acuity worse than $6 / 60$. The cause of the poor vision in 19 eyes includes old retinal detachment (17) and phthisis bulbi (2).

\section{Discussion}

In this article, we found similar primary and secondary anatomic success between two time periods despite differences in technique. In group A (2002-2005), retinopexy was achieved through cryotherapy and in group B (2011-2014) retinopexy was done using postoperative $532 \mathrm{~nm}$ laser photocoagulation. The anatomic success rate in this study was comparable with other studies. . $^{1,3,8,810-13}$ Avitabile et al evaluated the efficacy of cryotherapy vs transpupillary laser retinopexy in a randomized prospective study of 703 patients with RRD undergoing SB. ${ }^{14}$ The anatomic success rate was found to be similar among the two groups at 6 months postoperatively. ${ }^{14}$ Similarly, Lira et al reported similar anatomic success rates at 6 months in a prospective trial of 66 patients with RRD who had undergone SB and were randomly assigned to either intraoperative cryotherapy or postoperative laser retinopexy. ${ }^{15}$ The anatomic success rate at 10 weeks was similar between cryotherapy and postoperative laser retinopexy in a randomized control trial of 48 eyes undergoing SB for macular on RRD. ${ }^{15}$ While postoperative laser retinopexy have been reported to be associated with low incidence of PVR, ${ }^{16}$ there are reports suggesting that cryotherapy was associated with increasing rates of PVR..$^{17,18}$ Bonnet et al reported that the incidence of PVR was associated with the type and anatomy of the primary break. ${ }^{17}$ They found that in eyes with atrophic holes, oral dialysis, horseshoe tear with mobile posterior edge, and giant retinal tears, the incidence of PVR was not significantly different whether cryotherapy or laser was used for retinopexy. ${ }^{17}$ However, the incidence of PVR was significantly higher in the cryotherapy group in eyes with horseshoe tears with curled posterior edge and larger tear equal to or greater than 180 degrees. ${ }^{17}$ There are also reports that suggest that retinopexy may not be necessary following SB as long as all retinal breaks are situated on the buckle..$^{19,20}$
In a randomized controlled trial of 60 patients with retinal detachment caused by retinal break no larger than 1 clock hour, the anatomic success rate was $90 \%$ in the group that did not have retinopexy and $87 \%$ in the retinopexy group. ${ }^{19}$ There was no statically significant difference between these groups. ${ }^{19}$ The authors argue that no retinopexy is necessary to seal retinal breaks if all the retinal breaks and suspicious areas are situated squarely on the buckle. ${ }^{19}$ Banaee et al did not find significant effect of laser retinopexy on anatomic success rate of SB. ${ }^{21}$

Similar anatomic success rates for SB have been obtained whether SRF drainage procedures were used or not. ${ }^{8,21-23}$ In this study, drainage of SRF was predominant (94\%) in group A compared with group B (32\%) although the difference was not statistically significant $(P=0.857)$. SRF drainage was associated with the occurrence of subretinal and vitreous hemorrhage in this study similar to previous reports. ${ }^{8,22,23}$ Other studies have also reported the occurrence of retinal/ vitreous incarceration and retinal breaks with the drainage procedure. ${ }^{8,22}$ Noori et al reported that the only factor associated with anatomic failure of SB was subretinal hemorrhage associated with the drainage procedure. ${ }^{23}$

The primary anatomic success in this study $(70 \%$ in group A and $67.9 \%$ in group B) appears to be low compared with other studies. ${ }^{8}, 11$ Similarly, Yorston et al observed a lower primary anatomic success in East African population, although majority of the patients had vitrectomy and the success was determined at 8-week follow-up visit. ${ }^{24}$ They suggested that the poor anatomic success may be due to delayed presentation and high rates of complex cases such as PVR and giant retinal tears in their series. ${ }^{24}$ The lower primary anatomic success in this study may be due to the high rates of preoperative PVR grade C $(28.2 \%$ in group A and $33.3 \%$ in group B) compared with previous studies. ${ }^{25}$ The high rate of preoperative PVR in this study may be due to the high mean duration of RRD at presentation, younger age of our patients, and other unknown risk factors such as ethnic variation in the onset and severity of PVR. ${ }^{25-27}$ Mietz and Heimann reported that PVR often begins at 2 weeks and develops in a majority of cases within the first 2 months of onset of retinal diseases. ${ }^{26}$ The mean duration of RRD in our study was 105 days with a median of 42 days. Chandra et al reported that South Asian patients with RRD presented with severe phenotype compared with European Caucasians and suggested that the differences between these ethnic groups may be due to population stratification. ${ }^{27}$

In this study, PVR (in group A) and macular detachment (in group B) were found to have significant effect on anatomic 
success by multivariate analysis. Ahmadieh et al found the extent of retinal detachment and PVR as the factors that significantly influenced the anatomic success by stepwise multivariate analysis. ${ }^{11}$ In another report, macular on retinal detachment, better preoperative visual acuity, phakia, less extensive retinal detachment, and definite retinal break correlated with higher single operation anatomic success rate. ${ }^{8}$

There was a significant improvement in the postoperative visual acuity compared with the presenting visual acuity despite delay in presentations in both groups A and B. Late presentation of patients with RRD is commonly reported in African populations and other developing countries. ${ }^{10-13,28,29}$ A better mean postoperative visual acuity at final follow-up in group B compared with group A could be attributed to a host factor such as differences in baseline characteristics,

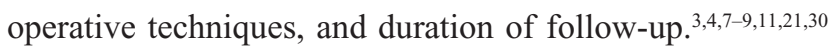
However, the patients in both groups had similar baseline characteristics such as age, duration of detachment, macular involvement, and quadrants of detachment. The main differences in operative techniques between these two groups are that group A had predominately the use of encircling bands (59\%), subretinal drainage (94\%), and exclusively intraoperative cryotherapy while group B had predominantly segmental buckle (67\%), nondrainage of SRF (68\%), and exclusively postoperative laser retinopexy. The differences regarding the use of buckle type and drainage techniques were however not statistically significant between these two groups. The only significant difference between the two groups was with respect to the type of retinopexy and duration of follow-up postoperatively. In a randomized controlled trial of cryotherapy vs laser retinopexy in 48 eyes undergoing SB for RRD, postoperative aqueous flare measured using laser photometry was significantly higher and visual recovery was slower in the cryotherapy group compared with postoperative laser although the visual acuity was not significantly different after 10 weeks postoperatively. ${ }^{31}$ Similarly, Lira et al reported no differences in visual acuity between cryotherapy and laser after 6 months postoperatively, although visual recovery was slower in the cryotherapy group. ${ }^{15}$ Salicone et al found a tendency for the group with better final visual acuity to have a longer follow-up period. ${ }^{8}$ While those with visual acuity better than or equal to $20 / 40$ had a follow-up of 21 months, those with acuity of 20/200 or worse had a follow-up of 12 months $(P=0.001) .{ }^{8}$ Visual acuity may continue to improve after several months or years after $\mathrm{SB} ., 30$ A significantly better postoperative visual acuity in group $B$ compared with group A may therefore be due to a significantly longer duration of follow-up observed in group B.
Hassan et al did not find significant decrease in the mean postoperative visual acuity until after 6 weeks duration of macular detachment. ${ }^{6}$ Another large retrospective series found that duration of macular detachment of 1 month or less before SB procedure had little effect on visual outcome. ${ }^{8}$ In this study, duration of macular detachment of 1 month or greater was associated with a significantly poorer visual outcome in both groups A and B. Salicone et al reported that macular detachment was the most important prognostic factor for anatomic success and visual outcome in SB. ${ }^{8}$

Up to $22 \%$ of fellow eyes had visual acuity worse than $6 / 60$ at presentation, and the cause was attributed to old retinal detachment which was not amenable to SB. There is the need to create awareness among the public and other health personnel on the importance of early and adequate eye examination to avoid late presentation. Awareness creation through health education on the symptoms of retinal detachment and promotion of positive health seeking behaviour among the Ghanaian population may result in earlier presentation before second eye involvement in RRD.

A longer follow-up period may be necessary to evaluate the anatomic and visual outcome after SB..$^{7,830,32}$ There is lack of reported data on the anatomic and visual outcome of $\mathrm{SB}$ in a West African population beyond 3-6 months. ${ }^{10,12,13}$ This study has shown that SB was still effective after 1 year postoperative in a West African population and that there was a tendency for improvement in visual acuity at 1 year and beyond similar to findings in other populations. , $^{7,30,32}$ There was, however, high rates of loss to follow-up in this study with only $15 \%(21 \%)$ available at 1 year in group A compared with $58(66.7 \%)$ in group B. It is reassuring that a lot more patients are reporting for follow-up in recent times (group B) compared with the earlier period (group A). The longer duration of follow-up in the recent period may be attributed to improvement in socioeconomic status of the Ghanaian population associated with increased awareness of eye conditions and accessibility to eye care services.

In recent times, primary vitrectomy is increasingly performed for patients with RRDs and vitrectomy is the main procedure performed following failure of SB surgery. . $^{8,15,23,32,33}$ Of 129 eyes who had recurrent or persistent RD following $\mathrm{SB}$, only six $(4.6 \%)$ were managed with revision of SB alone and $104(80.6 \%)$ had PPV. ${ }^{8}$ In this study, revision of SB was the second surgery performed following failure of the initial buckling procedure in both groups and has shown that favorable results can be achieved. While the number of surgeons and facilities adopting vitrectomy for RRD is increasing, $\mathrm{SB}$ still has a role in the developing countries including Ghana. 
There is a delay in SB surgery for RRD in some patients in developing countries due to financial constraints ${ }^{13}$ and PPV may be a source of further delay due to higher cost associated with the procedure.

\section{Limitations of the study}

There are several limitations associated with this study and include retrospective design, comparison of surgical interventions at different time periods, nonuniform documentation of clinical findings, and different surgeons. Despite these limitations, this study has provided data on anatomic and visual outcome of SB with different retinopexy techniques, success of revision of SB surgery, and longer duration of follow-up in a West African population.

\section{Conclusion}

The anatomic success rate of SB surgery was similar despite the use of different retinopexy techniques in the two time periods. The anatomic success rate did not change despite advances in techniques in the recent period. The final mean postoperative visual acuity was significantly better in the recent period compared with the earlier period and this was associated with a longer duration of follow-up. Revision of SBs can achieve favorable success in primary failure of SB in the era of primary vitrectomy for RRD. A prospective study is needed to better characterize the effect of baseline characteristics, operative techniques, and postoperative complications and duration of follow-up on the anatomic and visual success of SB surgery in the West African population with RRD.

\section{Disclosure}

The authors report no conflicts of interest in this work.

\section{References}

1. Sharma T, Challa JK, Ravishankar KV, Murugesan R. Scleral buckling for retinal detachment. Predictors for anatomic failure. Retina. 1994;14(4):338-343.

2. Tani P, Robertson DM, Langworthy A. Rhegmatogenous retinal detachment without macular involvement treated with scleral buckling. Am J Ophthalmol. 1980;90(4):503-508.

3. Tani P, Robertson DM, Langworthy A. Prognosis for central vision and anatomic reattachment in rhegmatogenous retinal detachment with macula detached. Am J Ophthalmol. 1981;92(5):611-620.

4. Wilkinson CP, Rice TA, editors. Michels Retinal Detachment. 2nd ed. St. Louis, MO: Mosby; 1997.

5. Ross WH. Visual recovery after macula-off retinal detachment. Eye. 2002;16(4):440-446.

6. Hassan TS, Sarrafizadeh R, Ruby AJ, Garretson BR, Kuczynski B, Williams GA. The effect of duration of macular detachment on results after the scleral buckle repair of primary, macula-off retinal detachments. Ophthalmology. 2002;109(1):146-152.
7. Liu F, Meyer CH, Mennel S, Hoerle S, Kroll P. Visual recovery after scleral buckling surgery in macula-off rhegmatogenous retinal detachment. Ophthalmologica. 2006;220(3):174-180.

8. Salicone A, Smiddy WE, Venkatraman A, Feuer W. Visual recovery after scleral buckling procedure for retinal detachment. Ophthalmology. 2006;113(10):1734-1742.

9. van Bussel EM, van der Valk R, Bijlsma WR, La Heij EC. Impact of duration of macula-off retinal detachment on visual outcome: a systematic review and meta-analysis of literature. Retina. 2014;34(10): 1917-1925.

10. Nwosu SN, Akudinobi CU. Outcome of surgery for rhegmatogenous retinal detachment in a nigerian eye hospital. Niger Postgrad Med J. 2014;21(4):315-318.

11. Ahmadieh H, Entezari M, Soheilian M, et al. Factors influencing anatomic and visual results in primary scleral buckling. Eur J Ophthalmol. 2000;10(2):153-159.

12. Alhassan MB, Rabiu MM, Olongusua Y, Ahmed A. Outcome of scleral buckling for primary rhegmatogenous retinal detachment in Nigeria. Med Sci Monit. 2005;11(12):CR589-CR593.

13. Oluleye T, Ibrahim O, Olusanya B. Scleral buckling for retinal detachment in Ibadan, Sub-Saharan Africa: anatomical and visual outcome. Clin Ophthalmol. 2013;7:1049-1052.

14. Avitabile T, Bartolotta G, Torrisi B, Reibaldi A. A randomized prospective study of rhegmatogenous retinal detachment cases treated with cryopexy versus frequency-doubled Nd:YAG laser-retinopexy during episcleral surgery. Retina. 2004;24(6):878-882.

15. Lira RP, Takasaka I, Arieta CE, Nascimento MA, Caldato R, Panetta H. Cryotherapy vs laser photocoagulation in scleral buckle surgery: a randomized clinical trial. Arch Ophthalmol. 2010;128(12):1519-1522.

16. van Meurs JC, Feron E, van Ruyven R, Mulder P, Veckeneer M. Postoperative laser coagulation as retinopexy in patients with rhegmatogenous retinal detachment treated with scleral buckling surgery: a prospective clinical study. Retina. 2002;22(6):733-739.

17. Bonnet M, Fleury J, Guenoun S, Yaniali A, Dumas C, Hajjar C. Cryopexy in primary rhegmatogenous retinal detachment: a risk factor for postoperative proliferative vitreoretinopathy? Graefes Arch Clin Exp Ophthalmol. 1996;234(12):739-743.

18. Bonnet M, Guenoun S. Surgical risk factors for severe postoperative proliferative vitreoretinopathy (PVR) in retinal detachment with grade B PVR. Graefes Arch Clin Exp Ophthalmol. 1995;233(12):789-791.

19. Figueroa MS, Corte MD, Sbordone S, et al. Scleral buckling technique without retinopexy for treatment of rhegmatogeneous: a pilot study. Retina. 2002;22(3):288-293.

20. Mahdizadeh M, Masoumpour M, Ashraf H. Anatomical retinal reattachment after scleral buckling with and without retinopexy: a pilot study. Acta Ophthalmol. 2008;86(3):297-301.

21. Banaee T, Hosseini SM, Ghooshkhanei H, Moosavi M, KhayyatzadehKakhki S. Anatomical and visual outcomes of three different scleral buckling techniques. J Ophthalmic Vis Res. 2009;4(2):90-96.

22. Hilton GF. The drainage of subretinal fluid: a randomized controlled clinical trial. Trans Am Ophthalmol Soc. 1981;79:517-540.

23. Noori J, Bilonick RA, Eller AW. Scleral buckle surgery for primary retinal detachment without posterior vitreous detachment. Retina. 2016;36(11):2066-2071.

24. Yorston DB, Wood ML, Gilbert C. Retinal detachment in East Africa. Ophthalmology. 2002;109(12):2279-2283.

25. Pastor JC. Proliferative vitreoretinopathy: an overview. Surv Ophthalmol. 1998;43(1):3-18.

26. Mietz H, Heimann K. Onset and recurrence of proliferative vitreoretinopathy in various vitreoretinal disease. Br J Ophthalmol. 1995; 79(10):874-877.

27. Chandra A, Banerjee P, Davis D, Charteris D. Ethnic variation in rhegmatogenous retinal detachments. Eye. 2015;29(6):803-807.

28. Peters AL. Retinal detachment in black South Africans. S Afr Med J. 1995;85(3):158-159.

29. Yorston D, Jalali S. Retinal detachment in developing countries. Eye. 2002;16(4):353-358. 
30. Liem AT, Keunen JE, van Meel GJ, van Norren D. Serial foveal densitometry and visual function after retinal detachment surgery with macular involvement. Ophthalmology. 1994;101(12):1945-1952.

31. Veckeneer M, Van Overdam K, Bouwens D, et al. Randomized clinical trial of cryotherapy versus laser photocoagulation for retinopexy in conventional retinal detachment surgery. Am J Ophthalmol. 2001; 132(3):343-347.
32. Goezinne F, La Heij EC, Berendschot TT, et al. Incidence of redetachment 6 months after scleral buckling surgery. Acta Ophthalmol. 2010;88(2):199-206.

33. Haugstad M, Moosmayer S, Bragadóttir R. Primary rhegmatogenous retinal detachment - surgical methods and anatomical outcome. Acta Ophthalmol. 2017;95(3):247-251.

\section{Publish your work in this journal}

Clinical Ophthalmology is an international, peer-reviewed journal covering all subspecialties within ophthalmology. Key topics include: Optometry; Visual science; Pharmacology and drug therapy in eye diseases; Basic Sciences; Primary and Secondary eye care; Patien Safety and Quality of Care Improvements. This journal is indexed on

Submit your manuscript here: http://www.dovepress.com/clinical-ophthalmology-journal

\section{Dovepress}

PubMed Central and CAS, and is the official journal of The Society of Clinical Ophthalmology (SCO). The manuscript management system is completely online and includes a very quick and fair peer-review system, which is all easy to use. Visit http://www.dovepress.com/ testimonials.php to read real quotes from published authors. 